\title{
SEXE, RACE ET COLONIES. LA DOMINATION DES CORPS DU XVE SIÈCLE A NOS JOURS
}

Pascal Blanchard, Nicolas Bancel, Gilles Boëtsch, Dominic Thomas y Christelle Taraud (coords.), París, La Découverte, 2018, 544 pp.

No es este un libro de fácil consulta, ni por sus dimensiones ni por su contenido. Sexe, race et colonies. La domination des corps $d u X V^{e}$ siècle à nos jours es una monumental obra colectiva de 1.200 imágenes y 17 capítulos sobre el nexo histórico entre sexualidad, categorías raciales y colonialismo. A través de cinco continentes y siete siglos de explotación sexual, el libro documenta sin reparos la ingente producción visual en la que se apoyaron colonizadores de orden diverso para construir a sus súbditos coloniales como «otros». Detrás del volumen hay un equipo de 97 investigadores que durante cuatro años ha rastreado 320 archivos y colecciones privadas de Europa y Estados Unidos. El resultado ha sido la selección de las 1.200 imágenes — grabados, pinturas, ilustraciones, carteles, postales, fotografías - que se incluyen en la obra. Estas valiosas fuentes primarias, en gran parte inéditas, se reparten entre los 17 capítulos escritos por los cinco coordinadores del volumen y sus colaboradores. Todo ello presentado en un libro de gran formato, con una altísima calidad en la reproducción de las imágenes.

Las publicaciones lujosamente ilustradas sobre sexualidad y colonialismo no son ninguna novedad en el mundo editorial francófono, como demuestran los títulos Harem colonial: Images d'un sous-érotisme de Malek Alloula (1981) y Bons Baisers des colonies: L'image de la femme dans la carte postale coloniale de Safia Belmenouar y Marc Combier (2007). ${ }^{1}$ Sexe, race et colonies es un heredero de estas obras, pero también de la investigación anterior de dos de sus coordinadores — Pascal Blanchard y Gilles Boëtsch— sobre los zoológicos humanos que en el siglo XIX expusieron algunos sujetos colonizados a las miradas europeas. ${ }^{2}$ Race, sexe et colonies tiene, sin embargo, un alcance mucho más am-

1. Malek Alloula, Harem colonial: Images d'un sous-érotisme, Ginebra y París, Editions Slatkine, 1981 y Safia Belmenouar y Marc Combier, Bons Baisers des colonies: L'image de la femme dans la carte postale coloniale, París, Editions Alternatives, 2007. La obra de Alloula ha sido traducida al inglés bajo el título de The colonial harem, Minneapolis, University of Minnesota Press, 1986.

2. Pascal Blanchard, Gilles Boëtsch y Nanette Jacomijn Snoep (coords.), Exbibitions: L'invention du sauvage, Arles, Actes Sud y París, Musée du quai Branly, 2011. 
bicioso. Los coordinadores recorren los siete siglos que les ocupan cronológicamente, a través de cuatro encabezados que representan distintas etapas de la relación entre colonizadores y colonizados: «Fascinaciones (1420-1830)», «Dominaciones (1830-1920)», «Descolonizaciones (1920-1970)» y «Mestizajes (después de 1970)». Si bien estas secciones un tanto arbitrarias tienen como objetivo examinar la evolución de la dominación sexual colonial en cinco continentes, dos espacios ocupan un lugar central en las páginas del volumen: el imperio francés y los Estados Unidos.

Los coordinadores admiten que el equipo de colaboradores tuvo dudas sobre la inclusión de las imágenes que presentan de forma más explícita la violencia sexual colonial. Muchas fueron excluidas de la publicación, especialmente las que muestran niñas y niños. Pese a esta bienvenida censura, el efecto global de la obra no deja de ser inquietante y acongojador: las páginas de Sexe, race et colonies son una avalancha de cuerpos tocados, torturados, expuestos y erotizados sin consentimiento. La sensación se ve aumentada por la gran cantidad de imágenes y el espacio que ocupan en comparación con el texto, que invita a ojear el libro más que a leerlo. En su afán enciclopédico, en su ambición cronológica y geográfica, la obra tiene tendencia a igualar las imágenes, haciendo invisibles las notables diferencias que existen entre ellas en tipología, origen y circulación, entre otros factores. El problema central del libro, sin embargo, no está tanto en las imágenes en sí como en la relación que los autores establecen entre estas y los textos. Aunque hay un innegable vínculo temático entre los dos, los capítulos raramente examinan las fuentes visuales que los rodean de forma directa. Las imágenes no están numeradas, lo que dificulta el trabajo de cualquier investigador que quiera hacer referencia a ellas en sus publicaciones.

A lo largo de las tres últimas décadas, el vínculo entre sexualidad y colonialismo ha sido ampliamente estudiado en diversos contextos coloniales. ${ }^{3}$ Como Ann Laura Stoler ha demostrado, la sexualidad no fue un aspecto marginal de la colonización, sino una parte fundamental de la empresa colonial. ${ }^{4}$ En este sentido, los capítulos de Race, sexe et colonies no siempre recogen adecuadamente la riqueza bibliográfica de este campo. Tienden a presentar colonizadores y colonizados como categorías impermeables al cambio histórico. Las barreras entre ambos no siempre fueron inexpugnables: a veces fueron obviadas, impugnadas o manipuladas por individuos de los dos grupos. El libro tampoco examina en detalle las distinciones internas de las dos categorías. ¿Hubo diferencias en la explotación sexual de colonizadores franceses y británicos? ¿Entre la de soldados y misioneros? ¿Afectó del mismo modo a todos los sujetos coloniales? La falta de atención a

3. Ver, por ejemplo, Antoinette Burton (ed.), Gender, sexuality and colonial modernities, Londres, Routledge, 1999; Ronald Hyam, Empire and sexual opportunity, Manchester, Manchester University Press, 1991; Philippa Levine, «Sexuality, gender, and empire», en Philippa Levine (ed.), Gender and empire, Oxford, Oxford University Press, 2009; y Anne McClintock, Imperial leather: Race, gender and sexuality in the colonial contest, Nueva York, Routledge, 1995.

4. Ann Laura Stoler, Race and the education of desire: Foucault's History of sexuality and the colonial order of things, Durham: Duke University Press, 1995; y, de la misma autora, Carnal knowledge and imperial power: Race and the intimate in colonial rule, Berkeley, University of California Press, 2002. 
estas cuestiones conduce a entender el poder colonial como más omnipotente e incontestable de lo que realmente era, negando la agencia de las mujeres y hombres colonizados que aparecen en estas fuentes visuales, así como la agencia de las comunidades que los rodeaban.

En la introducción del volumen, los coordinadores argumentan que es imposible «deconstruir» las poderosas jerarquías raciales y sexuales del colonialismo sin mostrar «las pruebas del crimen». Sin embargo, no está claro que mostrar — tampoco ver- signifique siempre entender. Al fin y al cabo, algunas de estas imágenes gozaban de una amplia circulación en el siglo XIX — como las postales que, con tiradas de hasta 100.000 ejemplares, hacían llegar retratos de mujeres negras desnudas al corazón de las metrópolis europeas. Todas estas imágenes persisten hasta nuestros días, a través de discursos y prácticas que presentan las mujeres no blancas - $-\mathrm{y}$, en menor medida, los hombrescomo seres de sexualidad desmedida, sumisa o exótica. El libro ciertamente contribuye a entender tanto los orígenes como las continuidades de estas construcciones coloniales, pero no siempre llega lo suficientemente lejos en su análisis.

Pese a sus defectos —o quizás gracias a ellos-Sexe, race, et colonies ha tenido la virtud de llevar el debate sobre la historia colonial a la esfera pública en Francia. Su publicación ha suscitado polémica en los medios de comunicación y en los medios sociales, donde activistas decoloniales, antirracistas y afrofeministas han acusados a los coordinadores de enaltecer la violencia sexual contra los colonizados y sus descendientes. Este tipo de controversia en torno a una obra de historia de gran formato no es nueva: recuerda la iniciada en 2000 con el libro Without sanctuary: Lynching photography in America, editado por James Allen. ${ }^{6}$ El volumen reproducía fotografías del linchamiento de negros frente a alegres multitudes blancas en Estados Unidos. Las voces contrarias a Without sanctuary lo encontraron degradante. Las críticas a Race, sex et colonies han ido más lejos, calificando la obra de pornografía que perpetúa los crímenes sexuales que pretende denunciar, revistiéndolos de un poder renovado. ${ }^{7}$ Diversos autores, mayoritariamente fue-

5. Pascal Blanchard et al., «Introduction: Sexe, race et colonies», en Pascal Blanchard, Nicolas Bancel, Gilles Boëtsch, Dominic Thomas y Christelle Taraud (coords.), Sexe, race et colonies. La domination des corps du XVe siècle à nos jours, París, La Découverte, 2018, pp. 17-19.

6. James Allen (ed.), Without sanctuary: Lynching photography in America, Santa Fe, New Mexico, Twin Palms Publishers, 2000.

7. Para las críticas más destacadas, ver Leila Alaouf, «'Sexe, race et colonies': le livre-corps souillé», Orient XXI, 14 de noviembre de 2018, <https://orientxxi.info/lu-vu-entendu/sexe-race-et-colonies-le-livrecorps-souille,2760>; Philippe Artières, «Sexe, race et colonies: livre d'histoire ou beau livre?», Libération, 30 de septiembre de 2018, <https://www.liberation.fr/debats/2018/09/30/sexe-race-et-colonies-livre-d-histoire-oubeau-livre_1682243>; Mélusine, «Un ouvrage sans ambition scientifique», Libération, 30 de septiembre de 2018, <https://www.liberation.fr/debats/2018/09/30/un-ouvrage-sans-ambition-scientifique_1682245>; y Daniel Schneidermann, «"Sexe, race et colonies”: Pascal Blanchard ne veut pas débattre», Arrêt sur images, 27 de septiembre de 2018, <https://www.arretsurimages.net/chroniques/sexe-race-et-colonies-pascal-blanchard-neveut-pas-debattre>. Para la respuesta de los coordinadores del volumen a las críticas, ver Gilles Boëtsch, «'Sexe, race et colonies' est bien un ouvrage d'histoire», Libération, 11 de octubre de 2018, <https://www.liberation.fr/ debats/2018/10/11/sexe-race-et-colonies-est-bien-un-ouvrage-d-histoire_1684693>; y Nicolas Bove, «Les auteurs de 'Sexe, race et colonies' reviennent sur les polémiques», Les Inrockuptibles, 8 de octubre de 2018, 
ra del mundo académico, han destacado especialmente el supuesto carácter voyerista de la obra, en un proyecto «pensado sin las víctimas». ${ }^{8}$ Es importante escuchar con atención estas voces, tanto las que llegan desde la disciplina histórica como las que no.

A pesar de la controvertida presencia de Race, sexe et colonies en la esfera pública en Francia, el libro apenas ha sido reseñado en las revistas académicas del país. ${ }^{9}$ Ha recibido, además, una atención muy escasa en lenguas más allá del francés. Es una pena, ya que tanto la obra como la polémica que ha suscitado son relevantes en muchos otros contextos, tanto académicos como no académicos. El debate que ha generado el libro nos invita a reflexionar sobre la herencia viva del pasado colonial en nuestras sociedades, así como sobre la importancia de las fuentes visuales en la producción del conocimiento histórico, tanto en la investigación como en la docencia. En este sentido, el volumen es un recurso particularmente rico para historiadores, historiadores del arte y antropólogos en la docencia en las aulas universitarias, siempre que las imágenes se contextualizan correctamente y se invite al alumnado a aproximarse a ellas con una mirada crítica. Race, sexe et colonies, proyecto imperfecto e incómodo, arroja una luz implacable sobre cómo la sexualidad colonial ha dado forma a nuestro mundo. En última instancia, es por eso que el libro resulta impactante: porque habla tanto de la era colonial como de la nuestra.

Teresa Segura-Garcia UPF-GRIMSE

(Barcelona, España)

<https://www.lesinrocks.com/2018/10/08/medias-actualite/societe/les-auteurs-de-sexe-race-et-colonies-reviennent-sur-les-polemiques/>.

8. Collectif Cases rebelles, «Les corps épuisés du spectacle colonial», Cases rebelles. Panafrorévolutionnaires, 26 de septiembre de 2018, <https://www.cases-rebelles.org/les-corps-epuises-du-spectacle-colonial>.

9. Ver las reseñas de Laurent Fourchard, «Sur les travers d'une entreprise mémorielle. P. Blanchard, N. Bancel, G. Boetsch, D. Thomas et C. Taraud (dir.), Sexe, race et colonies. La domination des corps du XVe siècle à nos jours, Paris, La Découverte, 2018, 544 pages», Politique africaine, vol. 152, num. 4, 2018, pp. 165-175; y Edward Ousselin, «Sexe, race et colonies: la domination des corps du XVe siècle à nos jours. Sous la direction de Pascal Blanchard, Nicolas Bancel, Gilles Boëtsch, Christelle Taraud et Dominic Thomas», French Studies, vol. 73, num. 3, 2019, pp. 502-503. 